\title{
The braincase and jaws of a Devonian "acanthodian" and modern gnathostome origins
}

Martin D. Brazeau

Subdepartment of Evolutionary Organismal Biology, Department of Physiology and Developmental Biology, Evolutionary Biology Centre, Uppsala University, Norbyvägen 18A, SE-752 36, Uppsala, Sweden

Modern gnathostomes (jawed vertebrates) emerged in the early Palaeozoic Era ${ }^{1}$, but this event remains unclear due to a scant early fossil record. The exclusively Palaeozoic “acanthodians” are possibly the earliest" ${ }^{2,3}$ gnathostome group and exhibit a mosaic of shark- and bony fish-like characters that has long given them prominence in discussions of early gnathostome evolution ${ }^{1}$. Their relationships with modern gnathostomes have remained mysterious owing partly to the fact that their un-mineralised endoskeletons rarely fossilized. Here I present the first-known braincase of an Early Devonian (approx. 418-412 mya) acanthodian, Ptomacanthus anglicus $^{4}$ and re-evaluate the interrelationships of basal gnathostomes.

Acanthodian braincases have previously been represented by a single genus, Acanthodes $^{5}$, which occurs more than 100 million years later in the fossil record. The braincase of Ptomacanthus differs radically from the osteichthyan-like braincase of Acanthodes $^{5}$ in exhibiting a number of plesiomorphic features shared 
with placoderms ${ }^{6,7}$ and some early chondrichthyans ${ }^{8,9}$. Most striking is its extremely short sphenoid region and its jaw suspension which displays features intermediate between some Palaeozoic chondrichthyans and osteichthyans. Phylogenetic analysis resolves Ptomacanthus as either the most basal chondrichthyan or as the sister group of all living gnathostomes. This new data alters earlier conceptions of basal gnathostome phylogeny and thus helps provide a more detailed picture of the acquisition of early gnathostome characters.

Most of the recent hypotheses of acanthodian relationships expressed in cladistic terms have focused on are the sister-group relations with chondrichthyans ${ }^{10}$ or osteichthyans ${ }^{5}$. All of these studies have presupposed acanthodian monophyly and stereotyped acanthodian endoskeletal morphology on Acanthodes, the latest-occurring and highly apomorphic ${ }^{1}$ genus. The assumption of acanthodian monophyly was initially based on their possession of paired and anal fin spines and a peculiar type of scale growth. A wealth of new data from unusual "acanthodians" and acanthodian-like "teleostomes" from northern Canada ${ }^{3,11-13}$ and Australia ${ }^{14}$ as well as discoveries of paired fin spines in basal chondrichthyans ${ }^{15,16}$, and osteichthyans ${ }^{17}$, have called acanthodian monophyly into question. This has placed acanthodians at the center of the growing debate on gnathostome origins, but there remains a reluctance to attempt explicit cladistic solutions. Ptomacanthus anglicus specimen NHM (Natural History Museum, London) P 24919a (Fig. 1) was collected from the Wayne Herbert Quarry Lagerstätte ${ }^{4}$ in Herefordshire, England. The site is Lockhovian in age (approx. 412-418 mya) placing Ptomacanthus among the earliest recorded articulated acanthodians. Ptomacanthus is assigned to the "Climatiidae", a division of the "Acanthodii", on the 
basis of its paired and median fin spine complement, paired pre-pelvic (or intermediate) fin spines and tessellated dermal cranial covering (further taxonomic review is found in the Supplementary Information). The specimen is a nearly complete, dorsoventrally flattened head and pharynx preserved as a natural mould in fine siltstone that has previously been acid etched and cast in rubber. Part and counterpart are preserved, with one side showing the specimen in palatal view, revealing the partial basicranium, the internal faces of the articulated palatoquadrates, the posterior half of the right Meckelian cartilage, and several incomplete branchial arches.

The braincase is preserved in two portions: a basisphenoid region anteriorly, and paired, unfused parachordal plates posteriorly. When examined under a dissecting microscope, the tissue has a rough crystalline surface comparable to the mineralised jaws known from Climatius ${ }^{4}$. However, there is no evidence of prismatic calcified tesserae as in chondrichthyans, as no significant biomineral remains in the natural moulds. The basisphenoid region is incompletely mineralised at its anterior end, but is delimited anteriorly by the intact tooth row. The anterior margin of this mineralization bears a deep medial notch corresponding to the hypophyseal opening. At the anterolateral margins of the basisphenoid are the articulations for the palatoquadrate. The sphenoid region narrows only slightly anterior to these articulations, suggesting that it continued forward between them to contact the ethmoid. The interorbital portion of the sphenoid is otherwise very broad and extends only a short way anterior to the articulations when compared with Acanthodes ${ }^{5}$ and basal osteichthyans ${ }^{18,19}$ in which it forms a narrow, elongate extension between the orbits ${ }^{5}$ (Fig. 2). In these aspects, Ptomacanthus resembles some placoderms ${ }^{7,20}$ which have very short ethmosphenoid regions. This is 
also seen in some early chondrichthyans ${ }^{9,21}$, but even there the pre-hypophysial extension of the sphenoid is comparatively longer than in Ptomacanthus. Flanking either side of the hypophysial opening is a foramen which gives off a posterolaterally directed groove (most clearly visible on the anatomical right side of the specimen). The right groove (left in figures) appears to continue as far as the lateral margin of the basicranium. These grooves and foramina are here interpreted as having accommodated the internal carotid arteries. This is based on their position near to the hypophysis and the angle of the associated grooves. A smaller but distinct groove extends anteriorly from the foramen for the right internal carotid and possibly carried the efferent pseudobranchial artery as in the arthrodire Buchanosteus ${ }^{22}$ and the early osteichthyan braincase assigned to Ligulalepis $^{23,24}$. Unlike basal osteichthyans ${ }^{18,19,24}$ and Acanthodes ${ }^{5}$, the basisphenoid of Ptomacanthus lacks evidence of spiracular grooves, again comparing more closely with chondrichthyans and placoderms.

The basicranial circulation of Ptomacanthus most resembles that in arthrodire placoderms ${ }^{6,7}$. The internal carotid foramina are widely separate from one another on a platybasic neurocranium (See Supporting Online Information for a discussion of the chondrichthyan Pucapampella, which Ptomacanthus also resembles). In most chondrichthyans and in Acanthodes ${ }^{5}$, the internal carotid arteries share a common medial foramen, usually shared with the hypophyseal opening. Some aspects of the basicranium cannot be identified with confidence but are worth mentioning. Evidence for a ventral cranial fissure is equivocal. Although the level corresponding to the position of this fissure in other gnathostomes (almost immediately posterior to the level of the hypophysis and postorbital processes) is mineralised, the 
large unpreserved region between the basisphenoid region and parachordals may correspond to this fissure. However, the dorsal portion of both palatoquadrates are missing from the specimen and their incomplete margins match closely the incomplete margins of the braincase. Thus, the unpreserved middle portion of the braincase may be taphonomic. Posterior to the anatomical right internal carotid opening is a smaller opening with a posterolaterally oriented groove. No corresponding feature can be confidently observed on the antimere, but the surface there is highly disrupted. Nevertheless, this foramen corresponds positionally to the opening for the palatine ramus of the facial nerve (N. VII), in many early gnathostomes ${ }^{6,9}$. Near the ventral midline of the basicranium, is a pair of anteroposteriorly elongate depressions that match the position of the pituitary vein foramina in certain arthrodires. Confirmation of the identity of these structures will have to await the discovery of more complete material. The paired palatoquadrate articulations are situated on anteriorly facing areas on the anterolateral corner of the basisphenoid, as in Acanthodes ${ }^{5}$. They are slightly anterior to the internal carotid foramina and are approximately at the same anteroposterior level as the hypophysial notch. This would, therefore, correspond to the basal articulation of osteichthyans, Acanthodes, and the early chondrichthyan Pucapampella ${ }^{8}$. However, they are situated very close to the ethmoid, as in early chondrichthyans (Figs. 1, 2). The parachordals are represented by paired trapezoidal, unfused mineralizations. They taper posteriorly to squared-off posterior ends, but there is no evidence of paired glenoids nor any blood vessel foramina. The unfused nature of the elements implies an unmineralised floor of the notochordal tunnel. This forms a deep anteriorly tapering notch as seen in Pucapampella ${ }^{8}$, but also some placoderms. Actinopterygians ${ }^{18}$ and 
Acanthodes also exhibit partial fusion of the parachordals, however the resulting notches are considerably smaller.

The neurocranium of Ptomacanthus is clearly distinct from its only other acanthodian counterpart, Acanthodes. In these respects, Ptomacanthus resembles more closely some placoderms and some basal chondrichthyans, rather than osteichthyans, suggesting that Ptomacanthus retains many plesiomorphic gnathostome attributes. Furthermore, while the exocranial (i.e. dermal) facial proportions of Ptomacanthus (and other similar “climatiid” acanthodians) $)^{4,5}$ are osteichthyan-like, this aspect is underlain by a neurocranium distinctly unlike any basal osteichthyan. Partial left and right palatoquadrates (Figs. 1, 3) are preserved and articulated to the neurocranium at the basal articulations. Their shape is similar to those of most other acanthodians, and basal chondrichthyans and osteichthyans with a large otic expansion giving a "cleaver-shaped" profile ${ }^{25}$. As in Acanthodes, the autopalatine region is short. Between the basal articulation and the ascending process of the palatoquadrate, the autopalatine exhibits a slight extension, by contrast with Acanthodes and basal osteichthyans, where the two are quite closely situated. The palatoquadrate of Ptomacanthus thus exhibits a process corresponding to ethmoid/orbital process of certain Palaeozoic sharks, but articulating with a surface on the braincase clearly corresponding to the basal articulation of osteichthyans, Acanthodes, and Pucapampella. This mosaic morphology supports the recently revived hypothesis that the orbital articulation and basal articulation are homologous structures ${ }^{9}$. Jarvik $^{19}$ cited the complete dental arcade of Ptomacanthus (Fig. 1) as evidence of a palatoquadrate symphysis as in modern elasmobranchs. However the palatoquadrates 
show no evidence of continuing mesially beneath the ethmoid. It is likely that the mesial part of the tooth row was supported on the ethmoid as is now considered to be plesiomorphic for chondrichthyans ${ }^{26}$.

A cladistic analysis of 45 ingroup taxa and two outgroup taxa was conducted based on 134 characters (See Supplementary Information). Ptomacanthus is placed as a basal stem chondrichthyan, but this result should be viewed with caution. A large part of the acanthodians, including Acanthodes, form a cohesive monophyletic group on the osteichthyan stem. However, the position of Ptomacanthus is problematic. Many of the supporting characters are not known or applicable in recognised crown-group chondrichthyans. Bayesian inference analysis (see Supplementary Information for results) does not resolve the position of Ptomacanthus beyond its relationships with the gnathostome crown node. The analysis was re-run for the endocranial character set and found that Ptomacanthus was resolved as the sister group of crown gnathostomes, on the basis of its short pre-hypophysial region. This data subset may well be compromised by the inclusion of less data, but its resolution also reflects a greater proportion of characters for which polarity is well established by outgroups. As far as the material can be scored, the neurocranial data from Ptomacanthus exhibits no significant endocranial synapomorphies with either lineage of the gnathostome crown group. Two additional significant results emerged from this analysis. First, Ligulalepis ${ }^{23,24}$ and Dialipina $^{27}$ are recovered as stem-osteichthyans in agreement with a recent phylogenetic analysis of Osteichthyes ${ }^{28}$. Second, placoderms are resolved as a basal gnathostome grade, as suggested by some other recent works ${ }^{28,29}$. Also, the failure to resolve the position of "diplacanthid" acanthodians results from a number of similarities with 
placoderms, such as the absence of an expanded otic process of the palatoquadrate (Fig. 3).

Current conceptions of gnathostome phylogeny depict a rather simplistic arrangement of nominally monophyletic and, apparently, morphologically disparate, groups ${ }^{1}$. The emerging picture of acanthodian (and perhaps placoderm) paraphyly does not overturn a general consensus about gnathostome interrelationships. Instead, it populates the long, naked internal branches, revealing a much richer picture of character evolution in early gnathostomes.

\section{Methods}

Analysis of the global dataset was performed using the heuristic search option, 10,000 random addition sequence replicates with 'maxtrees' set to automatically increase. One character (char. 33) was ordered, one character (char. 113) was parsimony-uninformative and excluded during all tree statistics calculations. Outgroup members were constrained as a paraphylum by inputting and enforcing a topological constraint tree. Bayesian inference analysis was performed employing a standard data model with $1.5 \times 10^{7}$ generations sampled every 100 generations. The 15,000 generation ‘burnin’ period was discarded. Analysis of the endocranial data set employed only taxa for which braincase data were adequately known. The search was performed using the branch-and-bound algorithm, outgroup constrained as a paraphylum, and 'maxtrees' set to increase automatically. Details of phylogenetic analyses are given in Supplementary Information.

1. Janvier, P. Early Vertebrates (Oxford, 1996).

2. Smith, M. M. \& Sansom, I. J. Exoskeletal micro-remains of an Ordovician fish from the Harding Sandstone of Colorado. Palaeontol. 40, 645-658 (1997). 
3. Hanke, G. F. Paucicanthus vanelsti gen. et sp. nov., an Early Devonian (Lochkovian) acanthodian that lacks paired fin-spines. Can. J. Earth Sci. 39, 1071-1083 (2002).

4. Miles, R. S. Articulated acanthodian fishes from the Old Red Sandstone of England, with a review of the structure and evolution of the acanthodian shouldergirdle. Bull. Brit. Mus. Nat. Hist. (Geol) 24, 111-213 (1973).

5. Miles, R. S. in Interrelationships of Fishes (eds. Greenwood, P. H., Miles, R. S. \& Patterson, C.) 63-103 (Academic Press, London, 1973).

6. Stensiö, E. Anatomical studies on the arthrodiran head, Part I. Kungl. Svensk. VetenskAkad. Handl. 9, 1-419 (1963).

7. Goujet, D. Les Poissons Placodermes du Spitsberg (Cahiers de Paléontologie (section Vertébrés), Editions du Centre National de la Recherche Scientifique, Paris, 1984).

8. Maisey, J. G. in Major Events in Early Vertebrate Evolution (ed. Ahlberg, P. E.) 263-288 (Taylor and Francis, London, 2001).

9. Maisey, J. G. Braincase of the Upper Devonian shark Cladodoides wildungensis (Chondrichthyes, Elasmobranchii), with observations on the braincase in early chondrichthyans. Bull. Am. Mus. Nat. Hist. 288, 1-103 (2005).

10. Nelson, G. J. Gill arches and the phylogeny of fishes, with notes on the classification of vertebrates. Bull. Am. Mus. Nat. Hist. 141, 475-552 (1969).

11. Gagnier, P.-Y. \& Wilson, M. V. H. Early Devonian acanthodians from Northern Canada. Palaeontol. 39, 241-258 (1996). 
12. Hanke, G. F. \& Wilson, M. V. H. in Recent Advances in the Origin and Early Radiation of Vertebrates (eds. Arratia, G., Wilson, M. V. H. \& Cloutier, R.) 189216 (Verlag Dr. Friedrich Pfeil, Munich, 2004).

13. Wilson, M. V. H., Hanke, G. F. \& Märss, T. in Major Transitions in Vertebrate Evolution (eds. Anderson, J. S. \& Sues, H.-D.) 122-149 (Indiana University Press, Bloomington and Indianapolis, 2007).

14. Burrow, C. J. \& Young, G. C. An articulated teleostome fish from the Late Silurian (Ludlow) of Victoria, Australia. Rec. W. A. Mus. Supplement 57, 1-14 (1999).

15. Young, G. C. Devonian sharks from south-eastern Australia and Antarctica. Palaeontol. 25, 817-843 (1982).

16. Miller, R. F., Cloutier, R. \& Turner, S. The oldest articulated chondrichthyan from the Early Devonian period. Nature 425, 501-504 (2003).

17. Zhu, M., Yu, X. \& Janvier, P. A primitive fossil fish sheds light on the origin of bony fishes. Nature 397, 607-610 (1999).

18. Gardiner, B. G. The relationships of the palaeoniscoid fishes, a review based on new specimens of Mimia and Moythomasia from the Upper Devonian of Western Australia. Bull. Brit. Mus. Nat. Hist. (Geol) 37, 173-428 (1984).

19. Jarvik, E. Basic Structure and Evolution of Vertebrates (Academic Press, London, 1980).

20. Ørvig, T. in Problèmes actuels de paleontologie: evolution des Vertébrés (ed. Lehman, J. P.) 41-71 (Paris, 1975). 
21. Schaeffer, B. The xenacanth shark neurocranium, with comments on elasmobranch monophyly. Bull. Am. Mus. Nat. Hist. 169, 1-66 (1981).

22. Young, G. C. New information on the structure and relationships of Buchanosteus (Placodermi: Euarthrodira) from the Early Devonian of New South Wales. Zool. J. Linn. Soc. 66, 309-352 (1979).

23. Basden, A. M., Young, G. C., Coates, M. I. \& Ritchie, A. The most primitive osteichthyan braincase? Nature 403, 185-188 (2000).

24. Basden, A. M. \& Young, G. C. A primitive actinopterygian neurocranium from the Early Devonian of southeastern Australia. J. Vertebr. Paleontol. 21, 754-766 (2001).

25. Schaeffer, B. in Problèmes actuels de paleontologie: evolution des Vertébrés 101109 (Paris, 1975).

26. Maisey, J. G. An evaluation of jaw suspension in sharks. Am. Mus. Novit. 2706, 117 (1980).

27. Schultze, H.-P. \& Cumbaa, S. L. in Major Events in Early Vertebrate Evolution (ed. Ahlberg, P. E.) 315-332 (Taylor and Francis, London, 2001).

28. Friedman, M. Styloichthys as the oldest coelacanth: implications for early osteichthyan interrelationships. J. Syst. Palaeontol 5, 289-343 (2007).

29. Johanson, Z. Vascularization of the osteostracan and antiarch (Placodermi) pectoral fin: similarities, and implications for placoderm relationships. Lethaia $\mathbf{3 5}$, 169-186 (2002).

Supplementary Information accompanies the paper on www.nature.com/nature.

Acknowledgements I thank M. Richter (NHM, London) for loans of specimens and access to collections; S. Davis, M. Friedman, D. Goujet, J. Long, J. Maisey, and G. Young for discussions on early 
gnathostome endocranial anatomy; P. Ahlberg and H. Blom for discussions and support during all phases of this work. Financial support for this work was provided by a Natural Sciences and Engineering Research Council of Canada Postgraduate Scholarship (NSERC PGS-D 331758-2006) awarded to the author.

\section{Author information}

Reprints and permissions information is available at npg.nature.com/reprintsandpermissions

The author declares having no competing financial interests.

Correspondence and request for materials should be addressed to the author at martin.brazeau@ebc.uu.se

\section{Figure legends}

Figure 1 | Ptomacanthus anglicus NHM P 24919a. a and b, Interpretive sketch of specimen (a) with accompanying photograph (b). c and d, Close-up photograph of neurocranium, tooth row, and anterior part of palatoquadrates (c) and interpretive sketch of neurocranium (d). B.art, basal articulation; Br.a, branchial arches; Ch, notochordal notch; Glen?, possible occipital glenoid; Hyp, hypophyseal opening; I.car.a, foramen for the internal carotid artery; L.Pq, left palatoquadrate; Mk, mineralised Meckelian cartilage; NVIIpal?, possible foramen for the palatine ramus of the facial nerve; Nc, neurocranial mineralizations; P.Ch., parachordal mineralizations; R.Pq, right palatoquadrate. Scale bar $=1 \mathrm{~cm}$.

\section{Figure 2 | Comparison of neurocranial proportions (ventral view) in early} gnathostome taxa drawn to same anterior-posterior length. Ptomacanthus braincase (delimited by heavy black lines) is shown inside the reconstructed head skeleton (delimited by thin lines). Horizontal blue line demarcates the approximate boundary between prechordal and parachordal regions of the braincase, with the position of the postorbital process used as a proxy. Arrows indicate position of palatoquadrate articulation shown in Figure 3. The position of 
this structure in Ptomacanthus is approximated by the position of the ascending process of the palatoquadrate. Illustrations modified after refs. 5, 7, 9 and 18. Na.ca., nasal capsules, or their corresponding position; V.cran.fi, ventral cranial fissure.

Figure 3 | Results of phylogenetic analyses and selected gnathostome palatoquadrates. a, Strict consensus trees of 2904 shortest trees from the global analysis (left. Treelength: 318 steps, C.I.: 0.44; R.I.: 0.76; R.C.: 0.34) and 30 most parsimonious trees from the endocranial data set (right. Treelength: 83 steps, C.I.: 0.64; R.I.: 0.85; R.C.: 0.54). b, Bothriolepis. c, Buchanosteus. d, Tetanopsyrus. e, Ptomacanthus. f, Cladodoides. g, Acanthodes. h, Mimia. Vertical arrow shows position of palatoquadrate-braincase articulation that correspond to the basipterygoid articulation shown in Figure 2. Double digits indicate percent bootstrap support, single digits show Bremer decay indices (when > 1). Illustrations modified from refs. 5, 18 and Supplementary Information references 40 and 107. 


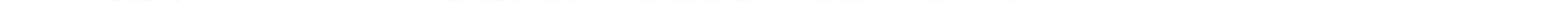




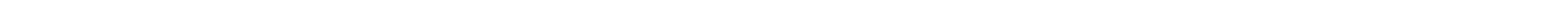




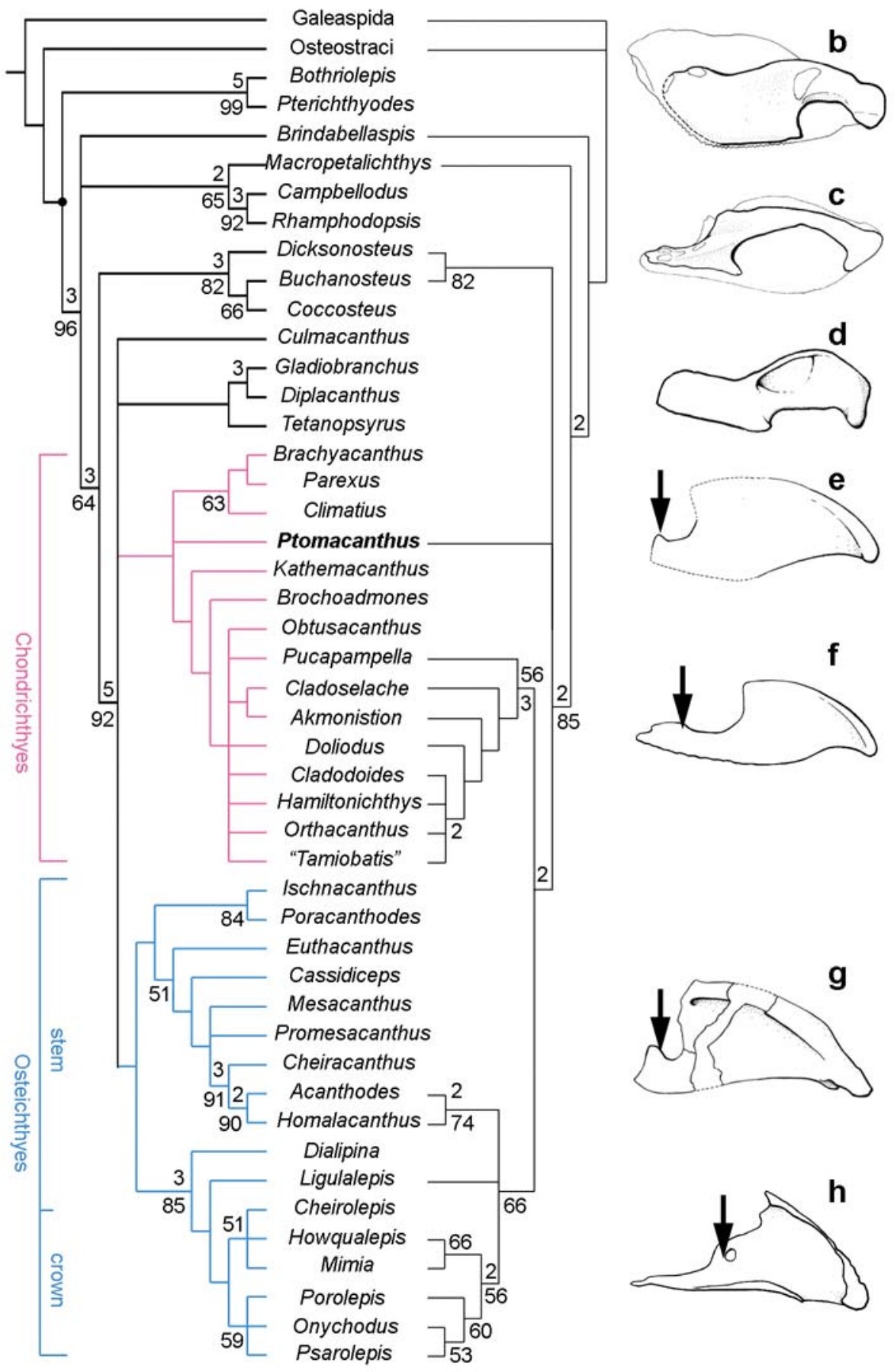

